\title{
A decision support system for identification of pests/disease of mango for U.P.
}

\author{
Meenakshi Malik*, A.K. Kanojia, R.V. Singh and Mukesh Sehgal
}

National Research Centre for Integrated Pest Management, New Delhi, India

\begin{tabular}{l} 
ARITCLE INFO \\
\hline Received : 17.01 .2018 \\
Accepted $: 27.03 .2018$ \\
\hline
\end{tabular}

\section{KEY WORDS :}

Mango, Agro-climatic zones, Decision support system, Insects/ pests
*Corresponding author: minaxi.2007@gmail.com

\begin{abstract}
Mango described as the "king of fruits", known for its delicious taste, high nutritive value, strong aroma is a prominent horticultural crop of India. The crop grown in diverse agro-climatic conditions face differential biotic and abiotic stress limiting the production and productivity of mango. Climate change is expected to provoke the changes in diversification and abundance of arthropods, geographical and temporal distribution of insect biotypes, insect pests, herbivore plant interactions, activity and abundance of natural enemies, species extinction and efficacy of crop protection technologies which in turn will have a major bearing on food and nutritional security. Severity of mango pests is influenced both by crop growth and prevailing weather. Developing a DSS for U.P. state based on the Agro-climatic zones is an initiative that can address the above issues to some extent and facilitate sustainable mango production. The state is being covered by 9 Agro-climatic Zones. Development of databases, information systems, expert system, Decision Support System has already taken place in Indian Council of Agriculture and Research but development of Decision Support System for mango according to different Agro-climatic zones of India is not yet available. To facilitate this communication it is necessary to have a DSS of the important crop for different zones.
\end{abstract}

How to view point the article : Malik, Meenakshi, Kanojia, A.K., Singh, R.V. and Sehgal, Mukesh (2018). A decision support system for identification of pests/disease of mango for U.P. Internat. J. Plant Protec., 11(1) : 115-118, DOI : 10.15740/HAS/IJPP/11.1/115-118. 